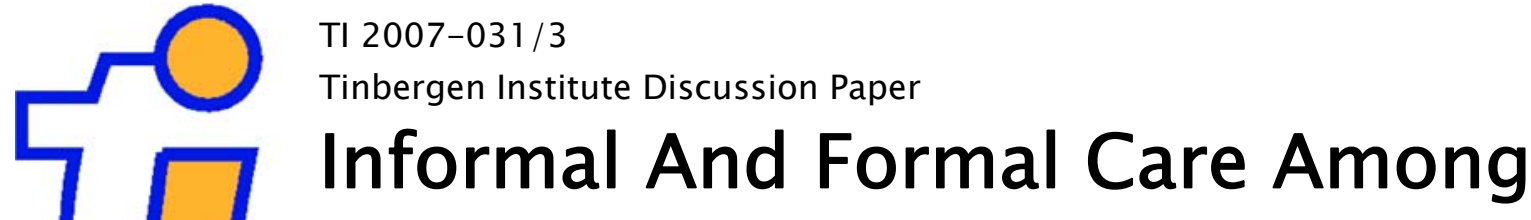 Single-Living Elderly In Europe
}

\author{
K. Bolin',2,3,4 \\ B. Lindgren $n^{1,2,3}$ \\ P. Lundborg $1,2,5,6,7$
}

' LUCHE (Lund University Centre for Health Economics), Lund, Sweden

2 Department of Health Sciences, Lund University, Lund, Sweden

3 Vårdal institute, Lund University, Lund, Sweden

4 Department of Economics, Lund University, Lund, Sweden

5 Department of Economics. Free University, Amsterdam, the Netherlands

6 Tinbergen Institute, Amsterdam, the Netherlands

7 NETSPAR, the Netherlands 


\section{Tinbergen Institute}

The Tinbergen Institute is the institute for economic research of the Erasmus Universiteit Rotterdam, Universiteit van Amsterdam, and Vrije Universiteit Amsterdam.

Tinbergen Institute Amsterdam

Roetersstraat 31

1018 WB Amsterdam

The Netherlands

Tel.: $\quad+31(0) 205513500$

Fax: $\quad+31(0) 205513555$

Tinbergen Institute Rotterdam

Burg. Oudlaan 50

3062 PA Rotterdam

The Netherlands

Tel.: $\quad+31(0) 104088900$

Fax: $\quad+31(0) 104089031$

Most TI discussion papers can be downloaded at http:/ /www.tinbergen.nl. 


\title{
INFORMAL AND FORMAL CARE AMONG SINGLE-LIVING ELDERLY IN EUROPE
}

\author{
Bolin $\mathrm{K}^{1,2,3,4}$,Lindgren $\mathrm{B}^{1,2,3}$,Lundborg $\mathrm{P}^{1,2,5,6,7}$ \\ ${ }^{1}$ LUCHE (Lund University Centre for Health Economics), Lund, Sweden \\ ${ }^{2}$ Department of Health Sciences, Lund University, Lund, Sweden \\ ${ }^{3}$ Vårdal institute, Lund University, Lund, Sweden \\ ${ }^{4}$ Department of Economics, Lund University, Lund, Sweden \\ ${ }^{5}$ Department of Economics. Free University, Amsterdam, the Netherlands \\ ${ }^{6}$ Tinbergen Institute, Amsterdam, the Netherlands \\ ${ }^{7}$ NETSPAR, the Netherlands
}

Abstract

The aims of this study were (1) to analyse whether informal care, provided by children or grandchildren to their elderly parents, and formal care are substitutes or complements, and (2) whether this relationship differs across Europe. The analyses were based on the newly developed SHARE (Survey of Health, Age, and Retirement in Europe) database. We found (1) that informal- and formal home care are substitutes, while informal care is a complement to doctor- and hospital visits, and (2) that these relationships in some cases differ according to a north-south gradient.

* Address for correspondence: Email: plundborg@feweb.vu.nl. This paper uses data from the early release 1 of SHARE 2004. This release is preliminary and may contain errors that will be corrected in later releases. The SHARE data collection has been primarily funded by the European Commission through the 5th framework programme (project QLK6-CT-2001-00360 in the thematic programme Quality of Life programme area). Additional funding came from the US National Institute on Aging (U01 AG09740-13S2, P01 AG005842, P01 AG08291, P30 AG12815, Y1-AG- 4553-01 and OGHA 04-064). Data collection in Austria (through the Austrian Science Foundation, FWF), Belgium (through the Belgian Science Policy Administration) and Switzerland (through BBW/OFES/UFES) was nationally funded. The SHARE data set is introduced in Börsch-Supan et al. 2005; methodological details are contained in Börsch-Supan and Jürges 2005. Additional funding for the Swedish participation in the SHARE data collection project came from the Bank of Sweden Tercentenary Foundation, the Swedish Council for Working Life and Social Research, and the Swedish Social Insurance Agency. The research reported in this paper was supported by a grant from the Swedish Council for Working Life and Social Research, which is gratefully acknowledged.

JEL classification: I11, I12, J22 


\section{INTRODUCTION}

Empirical studies have found a correlation between the amount of care and assistance supplied by close relatives or neighbours (informal care) and the amount of care supplied by the institutionalised health- and social-care systems (formal care). In two recent papers by Van Houtven \& Norton [1] and Charles \& Sevak [2], respectively, evidence was obtained suggesting that informal- and formal care were substitutes in the US. Previous studies have provided mixed evidence, however [3-5]. Whether informal care and formal care are substitutes or complements, naturally, depends on the exact purpose for using it. Basically, health care is utilised either in order to restore or to maintain health, whereas long-term care is provided in order to increase general welfare by facilitating the activities of daily living [6]. It seems unlikely that informal care is a substitute for formal care, when the purpose is to restore health in the case when highly qualified and specialised health care is demanded. On the other hand, when it comes to the day-to-day actions taken in order to assist in activities of daily living, it seems conceivable that informal- and formal care and assistance may be either substitutes or complements. For instance, informal care may make adverse future health outcomes less likely or formal care more productive, giving rise to a negative relationship between the two. A positive relationship may result, when informal care is comprised of advice and/or if the provider of informal care acts as the agent of the receiver of care $[1,7,8]$.

The relevance of studying the relationship between informal- and formal care is highlighted by the fact that the populations in the European countries are growing older, which is brought on by the simultaneous decline in mortality- and fertility rates, and which provokes the expectation that the demand for health care and care for the elderly will rise accordingly. The proportion of individuals aged 65 and over in the 25 member countries of EU is expected to rise from about today's 16 percent to 30 percent in the year 2050 [9]. Moreover, the proportion of individuals aged 80 and more is expected to almost triple, from 4.0 percent in 2004 to 11.4 percent in 2050 [9]. The increase in the share of elderly in the population is likely to induce a positive shift in the demand for health- and social care, which may put additional pressure on the performance and finance of existing health- and elderly care systems. In the highest age groups of the population there are many individuals who have long-standing physical and/or mental disability and are dependent on assistance with basic activities of daily living through various forms of long-term 
care. In addition, a number of studies have found that health-care costs rise as the proportion of elderly increases [10-12], even though the population age structure has usually been found insignificant in explaining inter-country differences in health-care expenditures [13]. There is, hence, a growing concern about increasing expenditure on long-term care services and health care over the next few decades, because of the continuing growth in the number and share of the oldest people [14].

Estimated trends on spending in long-term- and health-care for the elderly are highly sensitive, though, to trends in health status and disability of the old and very old of the population. Estimated shares of GDP on spending for the elderly are also highly sensitive to assumptions about the development of overall productivity, labour market participation, and the availability of informal care givers. For individuals with elderly parents, participation in the labour market and giving informal care and assistance are, of course, inter-related decisions [15-17]. In order to shape public-policy efforts aiming at elderly people's health and welfare, it is necessary to identify all the processes behind the utilisation of different components of health- and elderly care. Here, however, we shall concentrate on one of these issues, viz., whether informal and formal care and assistance are substitutes or complements.

A suitable theoretical framework for our analysis is the extension of Grossman's demand-for-health model [18] in order to include the provision of informal care developed by Van Houtven and Norton [1]. Their model is a static model of a game between parent and child: the parent chooses the amount of formal care (medical care in the model) given the amount of informal care provided by the child. Comparative static analysis of the optimal parental choice yields theoretical results which suggest when informal care is a substitute or a complement to formal care conditional on the qualitative content of formal care.

The model incorporates health as a utility-providing good. It is a function of a set of choice variables, which may be interpreted as a production function. Further, the child is able to directly influence the level of parental health by his or her choices of informal care, which introduces a strategic component into the process of making decisions (extensions of the demand-for-health model, which incorporate health-related decisions in a family context, were developed by Bolin et al. [19-20]). Formally, the Van Houtven and Norton model produces predictions in terms of a second-order derivative: the derivative of the marginal product of formal 
care (in the production of health) with respect to informal care. However, the model does not say anything about how each particular type of formal- and informal care corresponds to a specific functional form and parameterisation of the production function. Thus, whether or not formal care and informal care are complements or substitutes is an empirical question (which Van Houtven and Norton also pointed out in their paper). However, the general validity of the model - that the utilisation of formal- and informal care, respectively, is endogenously decided - should be taken into account in the empirical analysis.

There may be other motives for providing informal care, though, than those directly implied by the Van Houtven and Norton model. For instance, strategic effects imposed by the family-structure and/or effects on future bequests of current informal care provision. Thus, the processes, which generate the observed utilisation of informal- and formal care, respectively, are likely to differ between those who are cohabiting and those who live as singles [19-20]. ${ }^{1}$

Surveys and available time-use studies consistently estimate informal care and assistance to be in the range of 80 percent plus of all hours of care and assistance provided [14, p. 108]. So, the production of informal care is extensive. As long as the partner is alive, he or she is most often the informal caregiver, while adult children may take the main responsibility for assisting their single-living parents with basic activities of daily living. Thus, partners and children provide, respectively, 18 and 38 percent of all informal care provided in Austria, 32 and 28 percent in Germany, and 23 and 38 percent in Spain. For Sweden, there is no comparable information on partners; children account for 46 percent of all informal care provided, though [14, table A.6]. It should be observed, however, that definitions might differ among countries.

The objective of our present study was to examine the relationship between informal and formal care and assistance and to what extent the relationship differs across Europe according to a north-south gradient. There is substantial evidence that there are cultural differences between northern and southern Europe, which motivate such a focus. Southern European countries are commonly referred to as “strong-family-ties countries” and their northern European counterparts as "weakfamily-ties countries" [21]. The strength of family ties is usually discussed in terms of cultural patterns of family loyalties, allegiances, and authority, but it also concerns demographic patterns of intra-generational co-residence and patterns of support for 
the elderly. ${ }^{2}$ Kohli et al. [22] also associate the "weak-strong” dichotomy to a European North-South gradient. Here, the Scandinavian countries are found to have the "weakest" family ties, the Mediterranean countries the "strongest", whereas the continental countries lie somewhere in between. These patterns are also reflected by the fact that public spending on long-term care varies to a large extent between northern and southern European countries. For instance, spending on long-term care for females is typically highest in northern countries, such as Sweden and Denmark, who spend €19,867 and €22,336 per capita, respectively. Central European countries, such as Germany and Belgium spend less, €5,921 and €5,667, respectively. The lowest amounts are typically spent in southern European countries, such as Italy, who spends €4,764 per capita [23]. In 2000, public spending on long-term care as a percentage of GDP has been reported to be 2.74 in Sweden, 1.32 in Austria, 1.31 in the Netherlands, 0.95 in Germany, and 0.16 in Spain [14].

Moreover, cultural differences may be reflected also by a north-south gradient in the overall design of the welfare systems of Europe. Health-care systems, commonly referred to as national health services, are found in the Nordic countries and the UK; social-insurance systems are found in central Europe; whereas the systems established in the late 1970s and early 1980s in southern European countries may be seen as a "third way" [24, pp. 5-7]. True, there are differences in the design of organising and financing long-term and health care among countries and within countries that may not follow a north-south gradient $[14,25]$. If these differences have an impact of their own on the relation between formal and informal care, they may, of course, weaken our possibilities to detect a north-south gradient. It still seems to be a fruitful research issue to explore in this paper, however.

In our analyses, we made use of a recently developed cross-national database, SHARE (Survey of Health, Ageing, and Retirement), containing comparable information at the individual level from 11 European countries. Moreover, SHARE contains detailed information on the utilization of both informal and formal care. We considered informal care and assistance, supplied by children or grandchildren, and its respective effects on five different types of formal care, for those living as singles. ${ }^{3}$ In brief, we found (1) that informal care reduces the probability of utilisation of formal care provided in the household, and (2) that informal care increases the probability and the amount of utilisation of other types of formal care. Thus, our results suggest that informal and formal care both provided in 
the household are substitutes, while informal care provided in the household and formal care provided in hospitals or doctors' offices are complements. Moreover, the relationships seem to differ among the three European regions of study.

The paper proceeds as follows. First, the data will be presented. Second, the empirical methods used in the paper are described. Third, the results are presented. The paper concludes with a discussion of the policy-implications of our results, interpreted in the modified Grossman framework, provided by Van Houtven and Norton [1].

\section{DATA}

The Survey of Health, Ageing and Retirement in Europe (SHARE) is a multidisciplinary and cross-national micro database containing approximately 22,000 Europeans over the age of 50 years of age and their spouses. The first wave of data was collected in 2004. It contains representative samples from the noninstitutionalised population in respective participating country. The countries represent northern Europe (Denmark and Sweden), central Europe (Austria, France, Germany, Switzerland, Belgium, and the Netherlands), and southern Europe (Spain, Italy and Greece). Data from Belgium was not available at the time of writing. The database comprises information on health-related variables, for instance, self-reported health, physical functioning, cognitive functioning, psychological health, well-being, life satisfaction, and health care seeking behaviour, labour market variables, for instance, current work activity, job characteristics, opportunities to work past retirement age; economic variables, for instance, sources and composition of current income, wealth and consumption. Other variables include education, housing, and social support variables, for instance, assistance within families, informal care, transfers of income and assets, and social networks.

SHARE follows the design of the U.S. Health and Retirement Study (HRS) and the English Longitudinal Study of Ageing (ELSA). Response rates in SHARE ranged from 38\% in Switzerland to 69\% in France and the average response rate was 55\%. A description of methodological issues can be found in Börsch-Supan \& Jörges [26].

In our analyses, the sample was restricted to those who (1) lived as singles, (2) had at least one child, and (3) belonged to the age-group 50+. This left us with 3,559 observations. Single parents could be divorced, widowed, never married, 
or married but living separately. For singles 50+, children are the main providers of informal care. Based on SHARE data, it is estimated that children, including grandchildren, adopted, fostered and step children, provide $83 \%$ of all informal care for this group. ${ }^{4}$

\section{Dependent variables}

\section{Formal care}

We analysed formal care employing 9 separate dependent variables - 5 categorical variables indicating whether or not the respondent had any formal care utilisation, and 4 variables indicating the amount of utilisation - all for the past 12 months. The categorical variables were: (1) formal care provided in the household environment ${ }^{5}$; this variable was defined as having received any of the following categories of care: (a) professional or paid nursing or personal care, (b) professional or paid home help concerning domestic tasks that you could not perform yourself due to health problems, and (c) meals-on-wheels; (2) a doctor (GP or specialist) visit, (3) a GP visit, or (4) a specialist visit; (5) a hospital night. The variables indicating the amount of utilisation were: the number of (1) doctor visits, (2) GP visits, (3) specialist visits, and (4) hospital nights. Unfortunately, nursing home care was not included, since SHARE only covers the non-institutionalised population. In Table 1 and 2, descriptive statistics on formal care by country are shown.

\section{Explanatory variables}

\section{Informal care}

Informal care is comprised of the following components: (1) personal care, e.g. dressing, bathing or showering, eating, getting in or out of bed, and using the toilet, (2) practical household help, e.g. with home repairs, gardening, transportation, shopping, and household chores, and (3) help with paperwork, such as filling out forms, and settling financial or legal matters. They obviously consist of assistance as well as care, but for simplicity, all help will be named informal care in the following. ${ }^{6}$

In the survey, the respondent was first asked about the frequency of which he/she received informal care during the past 12 months. The alternatives given were: (1) almost every day, (2) almost every week, (3) almost every month, and (4) less often. Next, the respondent was asked to give an estimate of the number of hours of informal care received on a typical day/in a typical week/in a typical month/in the 
last twelve months. ${ }^{7}$ In order to make the answers comparable between respondents, we created a variable indicating for each respondent the number of hours past year that he/she received informal care. This variable was constructed as follows: If the respondent answered that he/she received informal care almost every day, we multiplied the number of hours received on a typical day by 365. If the respondent answered almost every week, the number of hours per week were multiplied by 52. In a similar vain, if the respondent answered almost every month, the number of hours per months were multiplied by 12. Finally, if the respondent answered that he/she received informal care less often than each month, he/she was asked to give an estimate of the total number of hours of informal care received past year. This estimate was kept as it was. Table 3 shows descriptive statistics on informal care.

Time diaries have been considered as the 'gold standard' for measurement of time provided for informal care [27]. Such diaries are not feasible in large surveys, such as SHARE, since they are too time-consuming. The recall method, used in SHARE, has been found to be a valid method, if it can be assumed that respondents take into account joint production, i.e. the possibility of performing several informal care tasks at the same time, when completing the recall questionnaire [27]. Robinson [28] found evidence that respondents corrected for such joint production when completing a recall questionnaire. It should also be observed that the data here relates to received (as opposed to provided) care and assistance.

\section{Other explanatory variables}

In Table 4, a description of our independent and dependent variables is given. The mean age of the respondents was 64 years, and 55 percent were women. Moreover, the typical respondent was born in the country in which the interview took place (92\%) and had on average 10 years of education. Four variables were used to capture the health status of the respondent. On average, the respondents had 1.53 health conditions (out of 14 listed) ${ }^{8}$, 1.5 symptoms (out of 11 listed) ${ }^{9}$, and 1.47 limitations (out of 10 listed) ${ }^{10}$. Self-reported health averaged 2.68 on a 1-5 scale were 1 indicated excellent health and 5 bad health. Smokers constituted 20 percent of the sample, and 28 percent reported being former smokers. The regressions also included country dummies, where Sweden was the omitted reference category. In the interacted models the country dummies were replaced with regional dummies. 


\section{EMPIRICAL METHOD AND SPECIFICATION}

Probit models were used to analyse the probability of having had (1) care provided in the household environment, (2) a doctor visit, (3) a GP visit, (4) a specialist visit, or (5) a hospital night, respectively. When estimating the quantities, conditional on strictly positive utilisation, OLS was used; in all cases the dependent variable was logged in order to reduce the influence of outliers. Formally, we may write the parent's utilisation of formal care as:

$$
F H_{i j}=f_{j}\left(I H_{i}, H_{i}, X_{i}, I_{i}, \varepsilon_{i j}\right), \quad j=1, \ldots, 9
$$

where $F H_{i j}$ denotes utilization of formal care of type $j$ by parent $I$ and $I H_{i}$ hours of informal care. In equation (1), $H_{i}$ denotes health status, $X_{i}$ socio-economic and demographic characteristics, $C_{i}$ the country, and $\varepsilon_{i j}$ an unobserved error term. The country dummies are included to capture some of the unobserved factors at the country level, such as the institutional framework, that vary between different European countries and that may affect formal health care utilisation.

The notion that informal- and formal care are used as inputs, either as substitutes or as complements, into the production of health investments suggests a high likelihood of there being unobserved variables, which affect both informal- and formal care. In order to take this into account, instrumental variables methods were employed. We followed the strategy used by Van Houtven \& Norton [1] of employing different child characteristics as instruments of informal care.

Variables assumed to affect the amount of informal care received from children and grandchildren, but not directly the amount of formal care by the parent were used as instruments. Thus, we used variables indicating the number of children, whether the oldest child lived more than 100 kilometres away, and the age of the oldest child. ${ }^{11}$ The number of children averaged 2.42 in the sample and the mean age of the eldest child was 37 years. Of these, 58 percent were employed. Further, the instruments described above were chosen since they passed tests of over-identification and relevance. Results from these tests are presented in Table 6.

In cases where the dependent variable was continuous, we used the 2SLS regression method. In cases where the dependent variable was dichotomous, we 
used the Amemiya Generalized Least Squares (AGLS) estimator, which estimates a probit model with a continuous endogenous explanatory variable. ${ }^{12}$

\section{RESULTS}

In Table 5, the results from our regressions are summarised. Results are shown using both the OLS/probit model and the instrumental variables OLS/probit model. In Table 5, only the marginal effects/coefficients of hours of informal care are presented in order to preserve space (the full results are available on request). Table 6 then summarises the results from the various econometrics tests employed in the instrumental-variables regressions.

\section{Formal home care}

In the first row of Table 5, the results from the regressions on formal home care are shown. First, using the ordinary probit model, a positive and significant relationship was obtained between hours of informal care and the probability of having received any formal home care, suggesting that informal- and formal care are complements. Second, using the instrumental variables probit estimator, we obtained a negative and significant correlation between informal- and formal care, suggesting that the two are substitutes.

Testing for the appropriateness of the employed instruments, we (1) rejected the null hypothesis that the instruments have no joint effect ( $F=30.59, \mathrm{p}<0.01)$, and we (2) were not able to reject the null hypothesis that the instruments were jointly valid; the instruments which were excluded from the main regression passed the test for overidentifying restrictions $(\mathrm{p}=0.94)$. We also tested the null hypothesis that informal care is exogenous [29]. The predicted residual from the first-stage regression was significant at the $1 \%$ level when included along with hours of informal care in the formal home care regression and, hence, the null hypothesis was rejected at the $1 \%$ level. The preferred specification is, hence, the one treating informal care as endogenous. The estimated marginal effect of informal care, -0.06, suggests that a 10 percent increase in informal care hours leads to a 0.6 percentage points decrease in the probability of using formal home care.

\section{Other formal care}


Next, we turn to the results from the regressions of other types of formal care than formal care provided in the household. As shown in Table 5, when estimated without taking the potential endogeneity of informal care into account, the results showed a positive and significant correlation between hours of informal care and (1) the probability of having any (a) specialist visits, and (b) hospital nights; and (2) the number of (a) doctor visits, and (b) GP visits. In the other cases, the effect was statistically insignificant.

When employing the IV-Probit/2SLS estimators, however, the effect of informal care was not statistically significant in any of the regressions on doctor visits or hospital nights. Testing for the appropriateness of the employed instruments we (1) rejected the null hypothesis that the instruments had no joint effect, and (2) were not able to reject the null hypothesis that the instruments were jointly valid; the instruments, which were excluded from the main regression in all cases, passed the test for over-identifying restrictions. We were not able, however, to reject the hypothesis that informal care was exogenous. Consequently, the preferred specification is the one treating informal care as exogenous in the regressions. It seems, thus, as if informal care complements formal care in the case of doctor visits and hospital nights. The estimated effect of informal care on doctor visits, 0.03, suggests that a 10 percent increase in hours of informal care leads to a 0.3 percent increase in the number of doctor visits among people having at least one visit. Concerning hospital nights, the estimated marginal effect of 0.01 suggests that a 10 percent increase in annual hours of informal care is associated with 0.1 percentage points decrease in the probability of having at least one annual hospital night.

\section{Interactions effects}

We also considered whether the results obtained above differed across different parts of Europe. For this purpose, the participating countries were first divided into three sub-groups, according to a north-south gradient. The first group consisted of the Nordic countries Sweden and Denmark (Nordic). The second group was comprised of countries in central Europe: Germany, France, Netherlands, Austria, Switzerland (Central). In the third group, the southern European countries Spain, Italy, and Greece (Southern) were included. In order to investigate whether the effects differed between these country groups, we created interaction variables between the amount of informal care received and country group. The same regressions as before were estimated 
including these interaction terms as explanatory variables. The omitted reference category was the country group southern Europe (and, hence, the interaction between southern Europe and informal care). The results are presented in Table 7 and 8. Again, we restrain the presentation - in this case to the estimated effects of the interaction terms and hours of informal care. ${ }^{13}$

We found that for the probability of having had a doctor, a GP, or a specialist visit, none of the interaction terms were statistically significant, suggesting that the effects did not differ significantly across Europe. Since the results in the previous section showed that exogeneity of informal care could not be rejected in the case of doctor visits and hospital nights, informal care was here treated as an exogenous variable.

In the case of formal home care, the interaction term between living in central Europe and informal care was statistically significant and positive. This suggests that the negative effect of informal care on formal home care is significantly lower for people in central Europe, compared to those residing in southern Europe. No differential effect was found for those living in the Nordic countries. The IVprobit model was used here, since the results from the previous section showed that the exogeneity of informal care was rejected in the case of formal home care. ${ }^{14}$

Regarding the quantities of formal health care, we found few significant interaction terms (Table 8). However, for those living in central Europe we found that the positive effect of informal care on the number of GP visits was significantly larger compared to those living in southern Europe. Finally, living in northern Europe was associated with a significantly smaller effect of informal care on the number of specialist visits.

\section{$70+$ only}

Since utilization of both informal and formal care is much more common among people aged 70 and above, our results may have been weakened by the fact that a substantial fraction of our sample did not utilize either type of care. In Table 9, the results from a sensitivity analysis including only people aged 70 and above are presented. Table 10 shows the results of the specification tests from the IVregressions; instruments used were exactly the same as the ones used above. ${ }^{15}$

As shown in Table 9, the results were robust to changes in the sample. The effects that were significant for the full sample were also significant for the 
restricted sample, even though the sample size was roughly halved. Moreover, in the specifications treating informal care as exogenous, the magnitude of the effect of informal care was virtually unchanged in all but one of the regressions. In the case of formal home care, the effect increased from 0.01 to 0.02 .

In Table 10, it is revealed that the exogeneity of informal care was only rejected in the regressions on formal home care and having any doctor visit. The former result was similar to the result obtained for the full sample. Treating informal care as endogenous in the case of formal home care resulted in a marginal effect of 0.09. This estimate was 50 percent greater than the corresponding marginal effect obtained for the full sample, i.e. -0.06 . In the case of having any doctor visit, the instrumental-variables estimate, which was the preferred one, was positive and insignificant.

In sum, the results were very similar. The most dramatic change was that the negative relationship between informal care and formal home care became roughly 50 percent greater when restricting the analysis to the older age group.

\section{DISCUSSION}

The results of our study emphasise the importance of testing and accounting for the potential endogeneity of informal care. Thus, not doing so resulted in a statistically significant and positive correlation between informal care and formal home care, while the sign of the correlation was reversed when endogeneity was taken into account. In the case of doctor visits and hospital nights, we were unable to reject the hypothesis that informal care is exogenous, though.

The magnitude of the effects obtained in our study might appear relatively small. In the case of formal home care, the estimated marginal effect of informal care, -0.06 , suggests that a 10 percent increase in informal care hours leads to a 0.6 percentage points decrease in the probability of using formal home care. Put differently, an increase in the annual hours of informal care by 13.2, from the mean of 132 (corresponding to an increase by 10 percent), would lead to a 13.4 percent likelihood of using formal home care from the mean of 14. Moreover, the estimated effect of informal care on doctor visits, 0.03, suggests that a 10 percent increase in hours of informal care leads to a 0.3 percent increase in the number of doctors visits among people having at least one visit. In other words, an increase in hours of 
informal care by 13.2 would only raise the number of doctor visits to approximately 8.60 from the mean 8.35. Finally, concerning hospital nights, the estimated marginal effect of 0.01 suggests that a 10 percent increase in annual hours of informal care is associated with 0.1 percentage points decrease in the probability of having at least one annual hospital night. In this case, a 10 percent increase in hours of informal care would lead to a 15.9 percent likelihood of having a hospital night from the mean of 16. It should be remembered, however, that even though the effects appear small, there might obviously still be a substantial impact in the case where future changes in the amount of informal care provided are large.

When comparing our results with those of Van Houtven \& Norton [1], we restrict the comparison to those aged 70 and above. Using data from the US Health and Retirement Study (with which SHARE data is consistently comparable), Van Houtven \& Norton [1] analysed the interrelations between formal care and informal care, given by children to their single-living $70+$ parents. Similar to our findings, informal care was found to be a substitute to formal home care; the hypothesis that informal care was exogenous in the regression on formal home care was also rejected. The marginal effect obtained by Van Houtven \& Norton in the latter case, -0.09, was actually identical to the one obtained in the present study, when we restricted the analysis to those aged 70 and above.

When it came to doctor visits and hospital stays, however, the effects differed by sign. While Van Houtven \& Norton [1] found a significant and negative relationship between informal care and physician visits, conditional on having any visit, we obtained the opposite result. Moreover, Van Houtven \& Norton found informal care to be a substitute to hospital nights (given that the individual had any hospital night), whereas in our study informal care showed a significant and positive relationship with the probability of having any hospital care but no significant effect on the number of hospital nights. It should be noted that Van Houtven \& Norton found informal care to be endogenous in determining formal home care, nursing home care, physician visits, and hospital care, while we rejected the exogeneity of informal care only in the case of formal home care.

We found some evidence of the north-south gradient, which is commonly claimed in the literature, due to cultural, and hence institutional, differences between northern and southern European countries [22]. Regarding formal home care, our results suggested that the negative effect of informal care on the 
former was significantly less in magnitude in central Europe compared to southern Europe. Also, the effect was less in magnitude in northern Europe, but the interaction effect was not statistically significant in this case. These results suggest that in regions with "strong" family ties, i.e. southern Europe, informal care to a greater extent substitutes for formal home care. This may reflect strong norms regarding family responsibilities, for instance, where family members are expected to supply the major part of home care.

A few caveats are in order. First, the lack of SHARE data on nursinghome care means that the total effect on the utilization of formal care resulting from changes in informal care remains to be settled. This is especially unfortunate, since nursing-home care constitutes a large share of the health- and social-care sectors in most European countries. It might be noted, though, that Van Houtven \& Norton [1] found informal care to be a substitute for nursing home care in a US setting. Second, it should, of course, be remembered that the results in this study concerns a sample of singles and that the policy implications, hence, only concern this group. In SHARE, 72 percent of the sample was married or living in registered partnerships, so our subsample represents a minority. Single-living elderly is an important group to analyse for policy purposes, however, since they lack the support from a spouse and are more exposed to the will of their children. Moreover, the number of single households is increasing in most European countries. Finally, the net effect of changes in the amount of informal care on long-run expenditures is not straightforward to assess. Some of the additional doctor visits that an informal care-giver invoke may be of a preventive nature, leading to less expenditures in the long run. Further analyses on this issue should opt for a dynamic perspective, for instance, by making use of the longitudinal SHARE data that eventually will be made available.

Variation in informal care across countries partly reflects variation in the availability of professional home-care services. Thus, the latter provides some of the desired variation in informal care needed to identify its effect on formal care. Admittedly, there is only imperfect information on the variation in accessibility of professional home- care services, leading to some unobserved heterogeneity. This might bias the results, if unobserved accessibility was correlated with the usage of both informal and formal care. Some of this unobserved heterogeneity would be picked up by the country dummies, however. Moreover, we controlled for the 
influence of unobserved heterogeneity by performing IV-regressions, where we also could check the endogeneity of informal care.

Policy-makers, not only in Europe, face a number of challenging issues with regard to future provision of health- and social care to the elderly. While the demand for care is likely to increase, there are at the same time demographic and socio-economic trends that are likely to decrease the availability of informal care. During the past decades, the average number of children per women has decreased in all European countries [30]. Consequently, future generations will have a smaller network to rely upon regarding the provision of informal care. Moreover, increased participation of women in the labour market may further reduce the availability of informal care. In Greece, for instance, the female percent of the labour force increased from 28 to 37 percent just between 1980 and 1998 [31]. Going further back in time, changes are obviously even more dramatic. Another trend, possibly affecting the supply of informal care, is the tendency in many European countries to raise their statutory retirement age [32]. This means that an increasing number of people in their 50s and 60s will still be working and, hence, have less time to act as informal caregivers. In addition, factors such as lower marriage rates, greater geographic mobility, and declines in intergenerational co-residence are factors contributing to changes in the supply of informal care over time, since most informal care-givers are spouses or children [33].

Norms and legislations surrounding informal care vary greatly across European countries. While in most countries, children are legally obligated to take care of their elderly parents, this is not the case in Sweden, for instance. The existence and extent of formalised support programmes for informal care-givers also vary. In several countries, the social-insurance system compensates informal care-givers taking time off work to care for their elderly parents. The extensiveness of these programmes, however, varies to a large extent; in France, for instance, 3 days per year are compensated, whereas in Italy, up to 25 days per day are compensated [34]. As a result of the demographic and socio-economic trends, norms will probably change, too. In this paper, we analysed whether informal- and formal care are substitutes or complements among elderly in Europe and whether this relationship differs across Europe. The analysis was conducted using a newly developed dataset on Europeans older than 50 years of age. To our knowledge, the paper is the first to study informal and formal care across Europe using a nationally representative data set and the first 
to examine differences among the European countries, especially following a northsouth gradient. Further studies should aim at improving our understanding also of the differences in effects between Europe and the US.

Even though informal care will never be able to solve the problems of the projected increases in public and private spending on health- and social care for the elderly, the knowledge contributed by this study produces essential pieces of information. Informal care always comes with a cost, however, with lower degree of market participation and lower wages [15-17]. In many European countries, dependency ratios are high while birth rates, labour market participation rates, and economic growth rates are low. In those countries, there is an obvious conflict of targets, introducing a trade-off between increasing the amount of informal care and increasing labour market participation. The most optimistic scenario, of course, would be one in which the health status of the old and the very old becomes substantially improved, which would ease the tension. So far, however, there is no clear evidence that this policy-makers' dream will come true [35-37]. 


\section{REFERENCES}

1. Van Houtven $\mathrm{CH}$, Norton EC. Informal care and elderly health care use. Journal of Health Economics 2004;23:1159-1180.

2. Charles KK, Sevak P. Can family caregiving substitute for nursing home care? Journal of Health Economics 2005;24:1174-1190.

3. Christianson JB. The evaluation of the national long-term care demonstration: the effect of channeling on informal caregiving. Health Services Research 1988;23:99-117.

4. Liu K, Manton KG, Aragon C. Changes in home care use by disabled elderly persons: 1982-1994. Journal of Gerontology B: Psychological Sciences Social Sciences 2000;55:245-S253.

5. Langa KM, Chernew ME, Kabeto MU, Katz SJ. The explosion in paid home care in the 1990s: who received the additional services? Medical Care 2001;39:147-157.

6. Scanlon WJ. Possible reforms for financing long-term care. Journal of Economic Perspectives 1992;6:43-58.

7. Greene V. Substitution between formally and informally provided care for the impaired elderly in the community. Medical Care 1983;21:609-619.

8. Lo Sasso A, Johnson R. Does informal care from adult children reduce nursing home admissions for the elderly? Inquiry 2002;39:279-297.

9. Eurostat. EU25 population rises until 2025, then falls. News release 8 April 2005. Eurostat press office. http://europa.eu.int/comm/eurostat/. 2005a.

10. Scheiber G, Poullier JP. International health care expenditures trends. Health Affairs 1987;8:169-177.

11. Culyer AJ. Health Expenditures in Canada. Ontario: Canadian Tax Institute, 1988.

12. Broomé P, Lindgren B, Lyttkens $\mathrm{CH}$, Ohlsson R. Health care and the Elderly. In Bengtsson T (ed.) Population, Economy and Welfare in Sweden. Berlin: Springer Verlag, 1994:155-186.

13. Gerdtham UG, Jönsson B. International comparisons of health expenditure: Theory, data, and econometric analys. In Culyer AJ, Newhouse JP (eds.) Handbook of Health Economics. Amsterdam: Elsevier, 2000:11-53.

14. OECD. Long-Term Care for Older People. Paris: OECD, 2005. 
15. Ettner S. The opportunity costs of elder care. Journal of Human Resources 1996;31:189-205.

16. Carmichael F, Charles S. The labour market costs of community care. Journal of Health Economics 1998;17:747-765.

17. Bolin K, Lindgren B, Lundborg P. Your next of kin or your own career? Caring and working among the 50+ of Europe. Working paper. Lund: Lund University Centre for Health Economics, 2007.

18. Grossman M. On the concept of health capital and the demand for health. The Journal of Political Economy 1972;80:223-255.

19. Bolin K, Jacobson L, Lindgren B. The family as the health producer - when spouses are Nash-bargainers. Journal of Health Economics 2001;20:349-362.

20. Bolin K, Jacobson L, Lindgren B. The family as the health producer - when spouses act strategically. Journal of Health Economics 2002;21:475-495.

21. Reher DS. Family ties in western Europe: persistent contrasts. Population and Development Review 1998; XXIV: 203-234.

22. Kohli M, Künemund H, Lüdicke J. Family structure, proximity and contact. In Börsch-Supan A, Brugiviani A, Jürges H, Mackenbach J, Siegrist J, Weber G (eds) Health, Ageing and Retirement in Europe. First Results from the Survey of Health, Ageing and Retirement in Europe. Mannheim: Research Institute for the Economics of Aging, 2005.

23. Economic Policy Committee and the European Commission (DG ECFIN). The impact of ageing on public expenditure: Projections for the EU25 Member States on pensions, health care, longterm care, education, and unemployment transfers (2004-2050). Special Report n 1/2006.

24. Freeman R. The Politics of Health in Europe. Manchester: Manchester University Press, 2000.

25. Blank RH, Burau V. Comparative Health Policy. Basingstoke: Palgrave Macmillan, 2004.

26. Börsch-Supan A, Jürges J (eds). Health, Ageing and Retirement in Europe Methodology. Mannheim: Research Institute for the Economics of Aging, 2005.

27. Van den Berg B, Spauwen P. Measurement of informal care: an empirical study into the valid measurement of time spent on informal caregiving. Health Economics 2006; 15: 447-460. 
28. Robinson JP. The validity and reliability of diaries versus alternative time use measures. In Juster FT, Stafford FP (eds) Time, Goods, and Well-Being. Ann Arbor: Institute for Social Research at the University of Michigan, 1985.

29. Rivers D, Vuong QH. 1988. Limited information estimators and exogeneity tests for simultaneous Probit models. Journal of Econometrics 1998; 39; 347366.

30. Eurostat. http://epp.eurostat.cec.eu.int/. 2005b.

31. World Bank. World Development Indicators 2000. Washington: World Bank, 2000.

32. MISSOC (Mutual Information System on Social Protection in the EU). http://europa.eu.int/comm/employment_social/soc-prot/missoc98/, 1998.

33. Heitmueller A. The chicken or the egg? Endogeneity in labour market participation of informal carers in England. Working paper, 2005.

34. Lamura G. Supporting carers of older people in Europe: a comparative report on six European countries. Paper presented at $11^{\text {th }}$ European Social Services conference - Venice, $2^{\text {nd }}-4^{\text {th }}$ July 2003.

35. Burström K, Johannesson M, Diderichsen F. The value of the change in health in Sweden 1980/81 to 1996/97. Health Economics 2003;12:637-654.

36. Lakdawalla D, Bhattacharya J, Goldman D. Are the young becoming more disabled? Health Affairs 2004;23:168-176.

37. Eurostat. Health Status Indicators. 2006.

38. Bernheim B, Schleifer A, Summers LH. The strategic bequest motive. Journal of Political Economy 1985;93:1045-1076.

39. Cox D, Rank MR. 1992. Inter-vivos transfers and intergenerational exchange. Review of Economics and Statistics 1992;74:305-314.

40. McGarry K, Schoeni RF. 1997. Transfer behavior within the family: Results from the asset and health dynamics study. The Journals of Gerontology Series B: Psychological and Social Sciences 1997;52B:82-92.

41. Norton EC, Van Houtven CH. Inter-vivos transfers and exchange. Southern Economic Journal 2006;73:157-172.

42. Bollen KA., Guilkey DK, Mroz TA. Binary outcomes and endogenous explanatory variables: tests and solutions with an application to the demand for contraceptive use in Tunisia. Demography 1995;32:111-131. 
43. Norton EC, Lindrooth R, Ennet ST. Controlling for the endogeneity of peer substance use on adolescent alcohol and tobacco use. Health Economics 1998;7:439-453. 


\section{TABLES}

Table 1. Descriptive statistics on formal care. Probability of having a doctor visit, GP visit, specialist visit, hospital visit, and home care.

\begin{tabular}{|c|c|c|c|c|c|c|c|c|c|c|}
\hline \multirow[t]{2}{*}{ Country } & \multicolumn{2}{|c|}{ Any doctor visit } & \multicolumn{2}{|c|}{ Any GP visit } & \multicolumn{2}{|c|}{$\begin{array}{l}\text { Any specialist } \\
\text { visit }\end{array}$} & \multicolumn{4}{|c|}{ Any hospital visit Any home care* } \\
\hline & Mean & sd & Mean & sd & Mean & sd & Mean & sd & Mean & sd \\
\hline Austria & 0.89 & 0.32 & 0.85 & 0.36 & 0.39 & 0.49 & 0.23 & 0.42 & 0.09 & 0.29 \\
\hline Germany & 0.93 & 0.26 & 0.90 & 0.30 & 0.51 & 0.50 & 0.18 & 0.38 & 0.08 & 0.28 \\
\hline Sweden & 0.76 & 0.43 & 0.67 & 0.47 & 0.29 & 0.46 & 0.18 & 0.39 & 0.12 & 0.33 \\
\hline Netherlands & 0.87 & 0.34 & 0.81 & 0.39 & 0.40 & 0.49 & 0.10 & 0.30 & 0.24 & 0.43 \\
\hline Spain & 0.93 & 0.26 & 0.87 & 0.34 & 0.38 & 0.49 & 0.15 & 0.36 & 0.13 & 0.34 \\
\hline Italy & 0.89 & 0.32 & 0.84 & 0.37 & 0.41 & 0.49 & 0.14 & 0.35 & 0.06 & 0.24 \\
\hline France & 0.95 & 0.21 & 0.89 & 0.31 & 0.43 & 0.50 & 0.17 & 0.37 & 0.23 & 0.42 \\
\hline Denmark & 0.82 & 0.38 & 0.80 & 0.40 & 0.15 & 0.35 & 0.15 & 0.36 & 0.23 & 0.42 \\
\hline Greece & 0.85 & 0.36 & 0.70 & 0.46 & 0.35 & 0.48 & 0.10 & 0.30 & - & - \\
\hline Switzerland & 0.90 & 0.30 & 0.84 & 0.36 & 0.34 & 0.48 & 0.14 & 0.34 & - & - \\
\hline Total & 0.88 & 0.33 & 0.81 & 0.39 & 0.37 & 0.48 & 0.16 & 0.36 & 0.14 & 0.35 \\
\hline
\end{tabular}

* Information on home care was unavailable for Greece and Switzerland 
Table 2. Descriptive statistics on formal care. Number of doctor visits, GP visits, specialist visits, and hospital visits, conditional on having at least one doctor visit last year.

\begin{tabular}{|c|c|c|c|c|c|c|c|c|}
\hline \multirow[t]{2}{*}{ Country } & \multicolumn{2}{|c|}{$\begin{array}{l}\text { Number of doctor } \\
\text { visits }\end{array}$} & \multicolumn{2}{|c|}{ Number of GP visits } & \multicolumn{2}{|c|}{$\begin{array}{l}\text { Number of specialist } \\
\text { visits }\end{array}$} & \multicolumn{2}{|c|}{$\begin{array}{l}\text { Number of hospital } \\
\text { nights }\end{array}$} \\
\hline & Mean & sd & Mean & sd & Mean & sd & Mean & sd \\
\hline Austria & 8.97 & 12.63 & 6.79 & 9.61 & 5.30 & 11.50 & 14.10 & 17.06 \\
\hline Germany & 9.80 & 11.53 & 7.13 & 9.48 & 5.11 & 7.01 & 19.23 & 21.34 \\
\hline Sweden & 4.33 & 4.71 & 3.21 & 3.19 & 3.46 & 4.61 & 7.59 & 10.04 \\
\hline Netherlands & 5.70 & 6.00 & 3.92 & 3.94 & 3.96 & 5.04 & 10.41 & 10.89 \\
\hline Spain & 12.73 & 15.10 & 10.59 & 12.69 & 5.50 & 10.08 & 9.80 & 11.42 \\
\hline Italy & 13.22 & 16.91 & 11.66 & 15.82 & 4.50 & 5.19 & 11.39 & 12.75 \\
\hline France & 7.68 & 5.57 & 6.48 & 4.56 & 3.16 & 3.80 & 11.72 & 14.12 \\
\hline Denmark & 5.19 & 6.68 & 4.52 & 5.77 & 3.52 & 3.95 & 20.30 & 46.91 \\
\hline Greece & 8.86 & 10.60 & 7.43 & 9.73 & 6.01 & 7.10 & 10.73 & 13.05 \\
\hline Switzerland & 15.39 & 7.08 & 4.42 & 6.79 & 3.03 & 3.18 & 8.12 & 8.23 \\
\hline Total & 8.35 & 11.02 & 6.70 & 9.39 & 4.59 & 7.31 & 13.23 & 20.91 \\
\hline
\end{tabular}


Table 3. Descriptive statistics on informal care.

\begin{tabular}{lllllll}
\hline Country & \multicolumn{2}{l}{$\begin{array}{l}\text { Annual } \\
\text { informal care }\end{array}$} & $\begin{array}{l}\text { hours } \\
\text { Mean }\end{array}$ & sd & Any informal care & $\begin{array}{l}\text { Annual } \\
\text { informal care given }>0\end{array}$ \\
\hline Austria & 121.78 & 469.53 & 0.38 & 0.48 & 324.15 & 722.97 \\
Germany & 152.78 & 667.72 & 0.40 & 0.49 & 382.39 & 1015.61 \\
Sweden & 50.08 & 329.50 & 0.42 & 0.49 & 119.60 & 502.03 \\
Netherlands & 56.02 & 219.55 & 0.42 & 0.49 & 132.42 & 322.77 \\
Spain & 206.37 & 1110.48 & 0.19 & 0.39 & 1091.38 & 2374.96 \\
Italy & 242.26 & 1295.64 & 0.21 & 0.41 & 1141.54 & 2638.88 \\
France & 145.49 & 735.60 & 0.33 & 0.47 & 444.86 & 1237.28 \\
Denmark & 52.95 & 218.43 & 0.40 & 0.49 & 131.68 & 329.67 \\
Greece & 232.09 & 711.78 & 0.38 & 0.49 & 614.68 & 1053.70 \\
Switzerland & 19.93 & 73.57 & 0.29 & 0.46 & 67.96 & 123.98 \\
& & & & & & \\
Total & 132.33 & 680.52 & 0.35 & 0.48 & 374.86 & 1105.26 \\
\hline
\end{tabular}


Table 4. Variables and descriptives of the sample in total.

\begin{tabular}{|c|c|c|c|}
\hline Variable & Description & Mean & Sd \\
\hline \multicolumn{4}{|l|}{ Dependent variables } \\
\hline Any home care & $\begin{array}{l}1 \text { if having received any of the following forms } \\
\text { of home care during the last } 12 \text { months: 1) } \\
\text { Professional or paid nursing or personal care } \\
\text { 2) Professional or paid home help, for domestic } \\
\text { tasks that you could not perform yourself due to } \\
\text { health problems } \\
\text { 3) Meals-on-wheels }\end{array}$ & 0.14 & 0.35 \\
\hline Any doctor visit & 1 if having any doctor visits past 12 months & 0.88 & 0.33 \\
\hline Any GP visit & 1 if having any GP visits last 12 months & 0.81 & 0.39 \\
\hline Any specialist visit & 1 if having any specialist visits last 12 months & 0.37 & 0.48 \\
\hline Any hospital nights & $\begin{array}{l}1 \text { if having any hospital nights during past } 12 \\
\text { months }\end{array}$ & 0.16 & 0.36 \\
\hline Number of doctor visits & Number of doctor visits past 12 months & 8.35 & 11.02 \\
\hline Log of doctor visits & Log of number of doctor visits past 12 months & 1.63 & 0.97 \\
\hline Number of GP visits & Number of GP visits past 12 months & 6.70 & 9.39 \\
\hline Log of GP visits & Log of number of GP visits last 12 months & 1.40 & 0.96 \\
\hline $\begin{array}{l}\text { Number of specialist } \\
\text { visits }\end{array}$ & Number of specialist visits past 12 months & 4.59 & 7.31 \\
\hline Log of specialist visits & Log of number of specialist visits last 12 months & 1.04 & 0.89 \\
\hline $\begin{array}{l}\text { Number of hospital } \\
\text { nights }\end{array}$ & Number of hospital nights past 12 months & 13.23 & 20.91 \\
\hline Log of hospital nights & Log of number of hospital nights last 12 months & 1.93 & 1.15 \\
\hline Explanatory variables & & & \\
\hline $\begin{array}{l}\text { Annual hours of } \\
\text { informal care }\end{array}$ & Total annual number hours of informal care & 132.33 & 680.52 \\
\hline $\begin{array}{l}\text { Log of annual hours of } \\
\text { informal care }\end{array}$ & $\begin{array}{l}\text { Ln }(1+\text { total hours of informal care received past } \\
12 \text { months })\end{array}$ & 0.65 & 1.76 \\
\hline Age & Age in years & 64.43 & 10.34 \\
\hline Age squared & Age $^{\wedge} 2$ & 4258.64 & 1387.92 \\
\hline Female & 1 if female & 0.55 & 0.50 \\
\hline Years of education & Total number of years of education & 10.01 & 4.52 \\
\hline Country of birth & 1 if born in country & 0.92 & 0.27 \\
\hline Health conditions & Number of health conditions out of 14 listed & 1.53 & 1.43 \\
\hline Self-reported health & $\begin{array}{l}\text { Self-reported health on a scale from } 1 \text { to } 5 \\
\text { (1=excellent, } 5=\text { bad) }\end{array}$ & 2.68 & 1.06 \\
\hline Symptoms & Number of symptoms out of 11 listed & 1.50 & 1.61 \\
\hline
\end{tabular}




\begin{tabular}{|c|c|c|c|}
\hline Mobility & $\begin{array}{l}\text { Number of limitations with mobility. arm } \\
\text { function \& fine motor function (out of } 10 \\
\text { described). }\end{array}$ & 1.47 & 2.12 \\
\hline Smoker & 1 if current smoker & 0.20 & 0.40 \\
\hline Former smoker & 1 if former smoker & 0.28 & 0.45 \\
\hline $\begin{array}{l}\text { Frequency of alcohol } \\
\text { consumption }\end{array}$ & $\begin{array}{l}\text { Frequency of alcohol consumption during past } 6 \\
\text { months (1-7 where } 1=\text { almost every day and } 7=\text { not } \\
\text { at all) }\end{array}$ & 4.32 & 2.27 \\
\hline Physical activity I & $\begin{array}{l}\text { Frequency of vigorous physical activity. such as } \\
\text { sports. heavy housework. or a job that involves } \\
\text { physical labour? (1-4, 1=more than once a week, } \\
4=\text { hardly ever, or never). }\end{array}$ & 2.50 & 1.33 \\
\hline Physical activity II & $\begin{array}{l}\text { Frequency of engagement in activities that } \\
\text { require a low or moderate level of energy such as } \\
\text { gardening. cleaning the car. or doing a walk? (1- } \\
4,1=\text { more than once a week, } 4=\text { hardly ever. or } \\
\text { never). }\end{array}$ & 1.55 & 1.00 \\
\hline Austria & 1 if interviewed in Austria & 0.10 & 0.31 \\
\hline Italy & 1 if interviewed in Italy & 0.13 & 0.33 \\
\hline Spain & 1 if interviewed in Spain & 0.10 & 0.29 \\
\hline Netherlands & 1 if interviewed in Netherlands & 0.14 & 0.34 \\
\hline Germany & 1 if interviewed in Germany & 0.14 & 0.35 \\
\hline Greece & 1 if interviewed in Greece & 0.09 & 0.29 \\
\hline Switzerland & 1 if interviewed in Switzerland & 0.05 & 0.21 \\
\hline France & 1 if interviewed in France & 0.07 & 0.26 \\
\hline Denmark & 1 if interviewed in Denmark & 0.08 & 0.27 \\
\hline $\begin{array}{l}\text { Sweden } \\
\text { Instruments }\end{array}$ & 1 if interviewed in Sweden & 0.11 & 0.31 \\
\hline Number of children & $\begin{array}{l}\text { Number of children (natural children, fostered, } \\
\text { adopted, and those of spouse/partner) }\end{array}$ & 2.42 & 1.28 \\
\hline Child 100 km & $\begin{array}{l}1 \text { if the oldest child lives more than } 100 \\
\text { kilometres away }\end{array}$ & 0.18 & 0.39 \\
\hline Age oldest child & Age of the oldest child & 37.37 & 11.24 \\
\hline
\end{tabular}


Table 5. Effect of logged hours of informal care received past 12 months on formal care.

\begin{tabular}{|c|c|c|c|c|}
\hline Dependent variable & $\begin{array}{l}\text { Probit/OLS } \\
\text { marginal } \\
\text { effect/coefficie } \\
\text { nt of informal } \\
\text { care (se) }\end{array}$ & $\mathrm{N}$ & $\begin{array}{l}\text { Ivprobit/ 2SLS } \\
\text { marginal } \\
\text { effect/coefficie } \\
\text { nt of informal } \\
\text { care (se) }\end{array}$ & $\mathrm{N}$ \\
\hline Any home care & $0.01(0.00)^{* *}$ & 2.856 & $-0.06(0.03)^{*}$ & 2.856 \\
\hline Any doctor visit & $0.00(0.00)$ & 3.559 & $0.01(0.02)$ & 3.545 \\
\hline $\begin{array}{l}\text { Log of doctor visits } \\
(\text { cond }>0)\end{array}$ & $0.03(0.01)^{* *}$ & 3.115 & $0.07(0.06)$ & 3.107 \\
\hline Any GP visit & $0.00(0.00)$ & 3.559 & $0.02(0.03)$ & 3.545 \\
\hline $\begin{array}{l}\text { Log of GP visits (cond > } \\
\text { 0) }\end{array}$ & $0.02(0.01)^{* *}$ & 2.909 & $0.04(0.06)$ & 2.902 \\
\hline Any specialist visit & $0.01(0.00)^{* *}$ & 3.559 & $0.04(0.04)$ & 3.545 \\
\hline $\begin{array}{l}\text { Log of specialist visits } \\
(\text { cond }>0 \text { ) }\end{array}$ & $0.01(0.01)$ & 1.423 & $-0.02(0.11)$ & 1.420 \\
\hline Any hospital nights & $0.01(0.00)^{* *}$ & 3.559 & $0.00(0.02)$ & 3.559 \\
\hline $\begin{array}{l}\text { Log of hospital nights } \\
\text { (cond }>0 \text { ) }\end{array}$ & $0.02(0.02)$ & 561 & $-0.06(0.11)$ & 560 \\
\hline
\end{tabular}

* significant at $5 \%$; ${ }^{* *}$ significant at $1 \%$

The regressions control for age, age squared, gender, whether born in country, years of education, number of health conditions, number of health symptoms, self-reported health, limitations on activity, smoking, drinking, sports activities, and other physical activities. In the instrumental variables regressions, two variables indicating the number of children and the whether the oldest child lived more than 100 kilometres away were used as instruments. An exception was the regressions on having any hospital nights, where the age of the oldest child was used instead of the variable indicating the number of children. The reason was that the specification using number of children as excluded instrument did not pass the test of overidentifying restrictions. Full results are available upon request. 
Table 6. Specification test of the instrumental variables regression.

\begin{tabular}{|c|c|c|c|}
\hline Dependent variable & $\begin{array}{l}\text { F-test of joint significance } \\
\text { of excluded instruments }\end{array}$ & $\begin{array}{l}\text { Test of exclusion } \\
\text { restrictions (p-value } \\
\text { of null of valid } \\
\text { exclusion } \\
\text { restrictions)* }\end{array}$ & $\begin{array}{l}\text { Test of null of } \\
\text { exogeneity (p-value } \\
\text { of null of exogeneity. } \\
\text { Wu-Hausman test). }\end{array}$ \\
\hline Any home care & $F(2.2873)=12.97$ & 0.94 & $<0.01$ \\
\hline Any doctor visit & $F(2.3519)=20.00$ & 0.17 & 0.57 \\
\hline $\begin{array}{l}\text { Log of doctor visits (cond } \\
>0 \text { ) }\end{array}$ & $F(2.3081)=18.34$ & 0.43 & 0.58 \\
\hline Any GP visit & $F($ 2. 3519) $=20.00$ & 0.36 & 0.53 \\
\hline $\begin{array}{l}\text { Log of GP visits (cond > } \\
\text { 0) }\end{array}$ & $F($ 2. 2876) $=20.99$ & 0.90 & 0.80 \\
\hline Any specialist visit & $F(2.3519)=20.00$ & 0.37 & 0.43 \\
\hline $\begin{array}{l}\text { Log of specialist visits } \\
(\text { cond }>0)\end{array}$ & $F(2.1394)=$ & 0.66 & 0.73 \\
\hline Any hospital nights & $F(2.3533)=28.02$ & 0.37 & 0.79 \\
\hline $\begin{array}{l}\text { Log of hospital nights } \\
\text { (cond }>0 \text { ) }\end{array}$ & $F(2.534)=$ & 0.54 & 0.45 \\
\hline
\end{tabular}

* significant at 5\%; ** significant at $1 \%$

In the probit regressions, the validity of the exclusion restrictions was tested by including all but one of the instruments in the structural equation that controls for endogeneity and testing their joint significance with a Wald test [42-43]. The test result does not depend on which instrument is left out. With valid exclusion restrictions, these should not be significant predictors of formal care after controlling for informal care. 
Table 7. Interaction terms. Effects of informal care on formal care. Probit coefficients (se).

\begin{tabular}{llllll}
\hline & $\begin{array}{l}\text { Any home } \\
\text { care }\end{array}$ & $\begin{array}{l}\text { Any doctor } \\
\text { visit }\end{array}$ & Any GP visit & $\begin{array}{l}\text { Any } \\
\text { specialist } \\
\text { visit }\end{array}$ & $\begin{array}{l}\text { Any hospital } \\
\text { nights }\end{array}$ \\
\hline $\begin{array}{lllll}\text { Hours of } \\
\text { informal care }\end{array}$ & -1.05 & -0.011 & -0.006 & 0.045 & 0.049 \\
& $(0.40)^{* *}$ & $(0.43)$ & $(0.31)$ & $(2.72)^{* *}$ & $(2.62)^{* *}$ \\
Hours * Nordic & 0.69 & 0.033 & 0.053 & 0.002 & 0.031 \\
& $(0.46)$ & $(0.84)$ & $(1.52)$ & $(0.07)$ & $(0.93)$ \\
Hours * Central & 0.89 & 0.016 & 0.026 & -0.039 & -0.002 \\
& $(0.39)^{*}$ & $(0.51)$ & $(0.98)$ & $(1.87)$ & $(0.08)$ \\
Central & 0.17 & 0.210 & 0.391 & 0.054 & 0.300 \\
Nordic & $(0.38)$ & $(2.51)^{*}$ & $(5.37)^{* *}$ & $(0.85)$ & $(3.65)^{* *}$ \\
& 0.61 & -0.350 & -0.107 & -0.641 & 0.216 \\
Observations & 2892 & 3559 & 3559 & 3559 & 3559 \\
\hline
\end{tabular}

* significant at 5\%; ** significant at $1 \%$ 
Table 8. Interaction terms. Effects of informal care on formal care. OLS coefficients (se).

\begin{tabular}{lllll}
\hline Interactions & \# doctor visits & \# GP & \# specialist visits & \# hospital nights \\
\hline Hours of & 0.03 & 0.00 & 0.05 & 0.04 \\
informal care & & & & \\
Hours * Central & 0.01 & $(0.01)$ & $(0.02)^{* *}$ & $(0.03$ \\
& $(0.01)^{*}$ & 0.04 & -0.03 & 0.01 \\
Hours * Nordic & -0.02 & $(0.02)^{*}$ & $(0.02)$ & $(0.04)$ \\
& $(0.02)$ & -0.01 & -0.07 & -0.10 \\
Central & -0.17 & $(0.02)$ & $(0.03)^{*}$ & $(0.06)$ \\
& $(0.04)^{* *}$ & -0.24 & -0.15 & 0.31 \\
Nordic & -0.60 & $(0.05)^{* *}$ & $(0.06)^{*}$ & $(0.15)^{*}$ \\
& $(0.05)^{* *}$ & -0.53 & -0.19 & 0.10 \\
\hline
\end{tabular}

* significant at 5\%; ** significant at $1 \%$ 
Table 9. Sensitivity analysis. Effect of logged hours of informal care received past 12 months on formal care among people aged 70 and above.

\begin{tabular}{|c|c|c|c|c|}
\hline Dependent variable* & $\begin{array}{l}\text { Probit/OLS } \\
\text { marginal } \\
\text { effect/coefficie } \\
\text { nt of informal } \\
\text { care (se) }\end{array}$ & $\mathrm{N}$ & $\begin{array}{l}\text { Ivprobit/ 2SLS } \\
\text { marginal } \\
\text { effect/coefficie } \\
\text { nt of informal } \\
\text { care (se) }\end{array}$ & $\mathrm{N}$ \\
\hline Any home care & $0.02 * *(0.00)$ & 1,395 & $-0.09 *(0.04)$ & 1,390 \\
\hline Any doctor visit & $-0.00(0.00)$ & 1,769 & $0.03(0.02)$ & 1,755 \\
\hline $\begin{array}{l}\text { Log of doctor visits } \\
(\text { cond }>0)\end{array}$ & $0.03^{* *}(0.01)$ & 1,609 & $0.00(0.06)$ & 1,605 \\
\hline Any GP visit & $0.00(0.00)$ & 1,769 & $0.03(0.02)$ & 1,755 \\
\hline $\begin{array}{l}\text { Log of GP visits (cond > } \\
\text { 0) }\end{array}$ & $0.02 *(0.01)$ & 1,525 & $-0.00(0.06)$ & 1,522 \\
\hline Any specialist visit & $0.01 *(0.00)$ & 1,769 & $0.05(0.04)$ & 1,760 \\
\hline $\begin{array}{l}\text { Log of specialist visits } \\
(\text { cond }>0)\end{array}$ & $0.01(0.01)$ & 720 & $0.00(0.09)$ & 718 \\
\hline Any hospital nights & $0.01^{* *}(0.00)$ & 1,769 & $0.03(0.03)$ & 1,764 \\
\hline $\begin{array}{l}\text { Log of hospital nights } \\
\text { (cond }>0 \text { ) }\end{array}$ & $0.02(0.02)$ & 336 & $0.05(0.11)$ & 336 \\
\hline
\end{tabular}

* significant at $5 \%$; ** significant at $1 \%$

The regressions control for age, age squared, gender, whether born in country, years of education, number of health conditions, number of health symptoms, self-reported health, limitations on activity, smoking, drinking, sports activities, and other physical activities. In the instrumental variables regressions, two variables indicating the number of children and the whether the oldest child lived more than 100 kilometres away were used as instruments. An exception was the regressions on having any hospital nights, where the age of the oldest child was used instead of the variable indicating the number of children. The reason was that the specification using number of children as excluded instrument did not pass the test of overidentifying restrictions. Full results are available upon request. 
Table 10. Sensitivity analysis. Specification test of the instrumental variables regression.

\begin{tabular}{|c|c|c|c|}
\hline Dependent variable & $\begin{array}{l}\text { F-test of joint significance } \\
\text { of excluded instruments }\end{array}$ & $\begin{array}{l}\text { Test of exclusion } \\
\text { restrictions (p-value } \\
\text { of null of valid } \\
\text { exclusion } \\
\text { restrictions)* }\end{array}$ & $\begin{array}{l}\text { Test of null of } \\
\text { exogeneity (p-value } \\
\text { of null of exogeneity. } \\
\text { Wu-Hausman test). }\end{array}$ \\
\hline Any home care & $F(2,2873)=10.58$ & 0.71 & $<0.01$ \\
\hline Any doctor visit & $F(2,3519)=16.84$ & 0.81 & 0.06 \\
\hline $\begin{array}{l}\text { Log of doctor visits (cond } \\
>0 \text { ) }\end{array}$ & $F(2,3081)=15.35$ & 0.37 & 0.84 \\
\hline Any GP visit & $F(2,3519)=21.01$ & 0.01 & 0.17 \\
\hline $\begin{array}{l}\text { Log of GP visits (cond > } \\
\text { 0) }\end{array}$ & $F(2,2876)=15.34$ & 0.96 & 0.69 \\
\hline Any specialist visit & $F(2,3519)=21.01$ & 0.81 & 0.26 \\
\hline $\begin{array}{l}\text { Log of specialist visits } \\
(\text { cond }>0)\end{array}$ & $F(2,1394)=6.64$ & 0.32 & 0.91 \\
\hline Any hospital nights & $F(2,3533)=24.84$ & 0.42 & 0.52 \\
\hline $\begin{array}{l}\text { Log of hospital nights } \\
\text { (cond }>0 \text { ) }\end{array}$ & $F(2, \quad 534)=4.81$ & 0.54 & 0.80 \\
\hline
\end{tabular}

* significant at $5 \%$; ** significant at $1 \%$

In the probit regressions, the validity of the exclusion restrictions was tested by including all but one of the instruments in the structural equation that controls for endogeneity and testing their joint significance with a Wald test $[42,43]$. The test result does not depend on which instrument is left out. With valid exclusion restrictions, these should not be significant predictors of formal care after controlling for informal care. 


\section{NOTES}

${ }^{1}$ In addition, it could be argued that the supply of informal care is increasing in the amount of the expected future bequest. For instance, parents could make future bequests conditional on the supply of informal care. Empirical findings support this view; wealthy parents are more frequently visited than poorer parents [38]. Moreover, some evidence has been obtained for exchange motives, i.e. financial transfers between parents and care-giving children when the parents are still alive [39-41].

${ }^{2}$ Reher [21] argues that the Muslim domination in southern Europe emphasized vertical relationships between generations, where children's care of their parents in old age and intra-generational co-residence are seen as a manifestation of a "strong family". The Reformation and Germanic tradition in northern Europe instead, according to Reher [21] contributed to the development of a weak family characterized by people who do not rely on their children in old age and by youths who detach themselves from their parents at relatively early ages.

${ }^{3}$ Children here included natural, fostered, and adopted children.

${ }^{4}$ This figure, naturally, varies between the included countries. The lowest fraction, $54 \%$, is found in Denmark and the highest, $93 \%$, is found in Italy.

${ }^{5}$ In the case of formal homecare it should be noted that Switzerland and Greece had missing observations at the time of writing.

${ }^{6}$ Moreover, due to the survey design, it was not possible to assess the frequency and intensity of the different categories of informal care separately.

${ }^{7}$ It should be noted that the interviewer was asked to round up the answers to full hours.

${ }^{8}$ The conditions considered were (1) heart attack, including myocardial infarction or coronary thrombosis or any other heart problem including congestive heart failure, (2) high blood pressure or hypertension, (3) high blood cholesterol, (4) a stroke or cerebral vascular disease, (5) diabetes or high blood sugar, (6) chronic lung disease such as chronic bronchitis or emphysema, (7) asthma, (8) arthritis including osteoarthritis or rheumatism, (9) osteoporosis, (10) cancer or malignant tumour including leukaemia or lymphoma but excluding minor skin cancers, (11) stomach or duodenal peptic ulcer, (12) Parkinson disease, (13) cataracts, (14) hip fractures or femoral fracture.

${ }^{9}$ The list of symptoms included (1) pain in back, knees, hips or any other joint, (2) heart trouble or angina, chest pain during exercise, (3) breathlessness, difficulty breathing, (4) persistent cough, (5) swollen legs, (6) 
sleeping problems, (7) falling down, (8) fear of falling down, (9) dizziness, faints or blackouts, (10) stomach or intestine problems, including constipation, air, diarrhoea, (11) incontinence or involuntary loss of urine. ${ }^{10}$ The list of limitation included (1) walking 100 metres, (2) sitting for about two hours, (3) getting up from a chair after sitting for long periods (4) climbing several flights of stairs without resting, (5) climbing one flight of stairs without resting (6) stooping, kneeling, or crouching, (7) reaching or extending your arms above shoulder level, (8) pulling or pushing large objects like a living room chair, (9) lifting or carrying weights over 10 pounds / 5 kilos, like a heavy bag of groceries, (10) picking up a small coin from a table. ${ }^{11}$ One may suspect that the location of children is endogenous, since children with sick parents may locate closer to their parents or vice versa. In Charles \& Sevak [2], however, no evidence was found for the hypothesis that children's location respond endogenously to parents' health.

12 The computations were performed using the IVPROB programme in STATA, which provides asymptotically efficient standard errors. In the first-stage regression, the endogenous explanatory variable is treated as linear functions of the instruments and the exogenous variables. In the second stage, the prediction from the first stage is included as an explanatory variable in the main equation, instead of the suspected original endogenous variable.

${ }^{13}$ Note that no country dummies were included in these regressions.

${ }^{14}$ In order to instrument for the interaction terms as well, the first-stage regression now included the interactions (a) between children characteristics and living in central Europe and (b) between children characteristics and living in northern Europe. The instruments, again, passed the relevant econometric tests. The results of the tests are available on request.

${ }^{15}$ The instruments passed the test of over-identifying restrictions in all cases but one. In the case of GP visits, the validity of the exclusion restrictions was rejected. 